\title{
Factors associated with adverse pregnancy outcome in Debre Tabor town, Northwest Ethiopia: a case control study
}

\author{
Abraham Sahilemichael Kebede ${ }^{1,2^{*}}$, Achenef Asmamaw Muche ${ }^{1,3}$ and Amelework Getinet Alene $e^{1,4}$
}

\begin{abstract}
Objective: The aim of this study was to assess the socioeconomic and demographic factors on adverse pregnancy outcomes.

Result: The mean age of cases was 42.2 ( \pm 13.26$)$ years and the mean age of controls was $34.5( \pm 12.23)$ years. Advanced maternal age, low educational status, and early sexual debut showed a significant association with an adverse pregnancy outcome. Mothers in the age group 35-44 years, AOR 2.54 (95\% Cl 1.27, 5.06), 35-44 years, AOR $2.79(95 \% \mathrm{Cl} 1.27,6.16)$ and Mothers with age 55 years and above AOR $4.18(95 \% \mathrm{Cl} 1.73,9.13)$ were more likely to have an adverse pregnancy outcome compared to mothers in the age group $\leq 24$ years. The low educational status was also found to have an implication on adverse pregnancy outcome. Those mothers with no formal education were two times more likely to develop adverse pregnancy outcome AOR $2.15(95 \% \mathrm{Cl} 1.41,2.81)$ and those in primary education AOR $1.6(95 \% \mathrm{Cl} 1.06,4.6)$ times more likely compared to those in higher education.
\end{abstract}

Keywords: Adverse pregnancy outcome, Stillbirth, Miscarriage, Debre Tabor town, Northwest Ethiopia, Case control

\section{Introduction}

According to World Health Organization report everyday more than 830 women die from pregnancy and or childbirth related complications around the globe [1]. In 2015 alone, roughly over 303,000 women died during and following pregnancy and childbirth [2].

Since the implementation of the MDGs, countries have showed remarkable progress in reducing unacceptably high maternal mortality. Published studies across countries have revealed that levels of maternal mortality halved since 1990 [1, 3, 4]. Despite the reduction of maternal mortality across the world MMR still continues to be the major index of the widening discrepancy in the level of care and the outcome of reproductive health between the advanced and developing countries. Over $99 \%$ of these deaths occurs in low-resource settings, and most could have been prevented [1].

\footnotetext{
*Correspondence: abrishya@yahoo.com

21000 Days Plus Project, Department of Reproductive and Health Service Management, Addis Ababa University, Addis Ababa, Ethiopia

Full list of author information is available at the end of the article
}

Globally, the adverse pregnancy outcome such as stillbirths, miscarriage, abortions and preterm births are being used as a maternal health indices [5]. More than $60 \%$ of preterm births take place in south Asia and subSaharan Africa [6]. Similarly, abortions and stillbirths are common adverse pregnancy outcomes that contribute substantially to poor maternal health outcome. Among an estimated 210 million pregnancies, 75 million end in abortion or stillbirth $[7,8]$.

Study from rural India found $19.8 \%$ preterm births, $1.7 \%$ abortions and $0.9 \%$ stillbirths. A similar study done in rural Uganda found $7.2 \%$ abortion and $1.3 \%$ in stillbirth [9-11]. A study conducted in Gondar University Hospital have also showed $14.3 \%$ of preterm and $7.1 \%$ of stillbirths $[12,13]$.

Evidence has also shown that adverse pregnancy outcomes had a strong and consistent association with biological, social and environmental factors. Many studies have found that socioeconomic status, income inequality and demographic factors are correlate with pregnancy outcomes. Also, a variety of social factors like maternal 
education, marital status and pregnancy intention have been linked to adverse pregnancy outcomes [14].

Older maternal age was associated with a higher risk of adverse pregnancy outcome [15]. Women who had primary education or above were less likely to have had adverse pregnancy outcomes compared to those with no education $[13,16]$.

The overall aim of this study was to assess the association between different sociodemographic characteristics and adverse pregnancy outcomes.

\section{Main text}

\section{Study design, period and setting}

Community based Unmatched case control study was conducted from January to June 2015 in Debre Tabor town. The town is located $667 \mathrm{kms}$ away from Addis Ababa the capital of Ethiopia. According to the 2010 Central Statistical Agency (CSA) report the population of Debre Tabor town is estimated to be 78,703 (37,682 males and 41,021 females) [17]. The town is divided into 4 administrative kebeles (the smallest administration unit in Ethiopia). Study participants, both cases and controls were recruited at household level.

\section{Sample size}

The sample size was calculated using a two population proportion formula to determine the number of participants. The proportion of having no formal education, being unemployed and unwanted pregnancy was used to determine the sample size. Unwanted pregnancy in the outcome induced abortion brought a higher sample size among other computed explanatory variables. The following parameter were used: 95\% confidence level, $80 \%$ power and proportion of women who had a history of abortion among unwanted pregnancies from a study done in southern Ethiopia $75.5 \%$ and the odds of induced abortion among wanted pregnancy which was found to be 0.44 were taken into consideration to calculate the minimum sample size [18]. The final calculated sample size with $10 \%$ contingency was 620 , equally shared among cases and controls $(\mathrm{n} 1=\mathrm{n} 2=310)$.

\section{Data collection and management}

Data collectors were trained and employed for the data enumeration. The standard questionnaire to collect the data were designed in English and translated to the local language, Amharic, by a language expert and transcribed back to English to check for consistency. The interview was held in a secluded room after the study participant consented to participate in the study. During the data collection period on spot checking and monitoring was done.

\section{Outcome variable}

History of adverse pregnancy outcomes (preterm, miscarriage, stillbirth and abortion), from the recent pregnancy history was recorded using a detailed interviewer questionnaire. Outcome variable ascertainment was self-report by the study participants. In this study, the Adverse pregnancy outcome was defined as mothers experienced at least one type of the following (preterm, miscarriage, stillbirth and/or abortion) was considered as a case and controls were women who never experienced one of the above situation.

Stillbirth is defined as the death of the fetus in the uterus before birth at or after 28-week gestational age [19].

Preterm all births before 37 gestational weeks or fewer than 259 days since the first day of a woman's last menstrual period [19].

Miscarriage spontaneous fetal loss before 22 week of gestation [20].

Abortion is the termination or initiation of termination of pregnancy before reaching viability (before 28 weeks of gestation or less than $1 \mathrm{~kg}$ fetal weight) [21].

\section{Statistical analysis}

STATA version 13 was used to analyze the finding of this study. Descriptive statistics and bivariate analysis was done. Further multiple logistic regression analysis was done to eliminate for potential confounding effect of different socioeconomic and demographic variables.

\section{Result}

This study included 310 cases and 310 controls. The mean age of cases was $42.2( \pm 13.26)$ years and mean age of controls $34.5( \pm 12.23)$ years. Seventy percent of cases and $65.2 \%$ of controls were unemployed. The majority $56 \%$ of the cases and more than $55 \%$ of the controls had no formal education; while only $2 \%$ of cases and $4.5 \%$ of the controls attended higher education. The majority of the cases and controls $32.3 \%$ and $48 \%$ respectively were in a relationship for less than 5 years. The different socio-demographic and economic characteristics are given in Table 1.

In our study, urban residents were majority in both groups. Sixty-three percent of cases and $73.2 \%$ of controls were urban dwellers. The majority of study participants were Christian in religion in both groups. And also the majority of the study participants in both the cases and controls were from the Amhara ethnic group. Both in the case and control group's majority, $96.8 \%$ and $95 \%$ of the cases and controls had previous history of marriage. Sexual debut was significantly different between the cases and controls. The majority of the cases $28 \%$ initiated sex at the age between 15 and 17 years while $66 \%$ of controls initiate sex after age of 18 years and above. 
Table 1 Sociodemographic characteristics of cases and controls among women in child bearing age group, Debre Tabor town, Northwest Ethiopia

\begin{tabular}{|c|c|c|c|c|c|}
\hline Variables & Category & Cases, $\mathrm{n}=310(\%)$ & Control, $n=310(\%)$ & Total, n= $620(\%)$ & $P$ value \\
\hline \multirow[t]{5}{*}{ Maternal age } & $\leq 24$ & $22(7.1)$ & $52(16.8)$ & $74(12)$ & 0.00 \\
\hline & $25-34$ & $79(25.5)$ & $139(44.8)$ & $218(35)$ & \\
\hline & $35-44$ & $80(25.8)$ & $60(19.35)$ & $140(22.6)$ & \\
\hline & $45-54$ & $68(22)$ & $38(12.3)$ & $106(17.1)$ & \\
\hline & $\geq 55$ & $61(21.9)$ & $21(6.8)$ & $82(13.2)$ & \\
\hline \multirow[t]{2}{*}{ Residence } & Rural & $112(36.1)$ & $83(26.8)$ & $195(31.5)$ & 0.012 \\
\hline & Urban & $198(63.9)$ & $227(73.2)$ & $425(68.6)$ & \\
\hline \multirow[t]{2}{*}{ Religion } & Christian & $265(85.5)$ & $258(83.2)$ & $523(84.4)$ & 0.439 \\
\hline & Muslim & $45(14.5)$ & $52(16.8)$ & $97(15.6)$ & \\
\hline \multirow[t]{3}{*}{ Ethnicity } & Amhara & $292(94.2)$ & $294(94.84)$ & $586(94.5)$ & 0.586 \\
\hline & Oromo & $5(1.6)$ & $7(2.3)$ & $12(1.9)$ & \\
\hline & Tigre & $13(4.2)$ & $9(3)$ & $22(3.5)$ & \\
\hline \multirow[t]{4}{*}{ Educational status } & No formal education & $174(56)$ & $171(55.2)$ & $345(55.6 \%)$ & 0.125 \\
\hline & Primary education & $94(30.3)$ & $79(25.5)$ & $173(28 \%)$ & \\
\hline & Secondary education & $36(12)$ & $46(14.8)$ & $82(13.2 \%)$ & \\
\hline & Higher education & $6(2)$ & $14(4.5)$ & $20(3.2)$ & \\
\hline \multirow[t]{2}{*}{ Employment status } & Unemployed & $218(70.3)$ & $202(65.2)$ & $420(67.7)$ & 0.169 \\
\hline & Employed & $92(30)$ & $108(34.8)$ & $200(32.3)$ & \\
\hline \multirow[t]{4}{*}{ Family Income categorized } & $\leq 560$ & $99(32)$ & $70(22.6)$ & $169(27.3)$ & 0.03 \\
\hline & $561-900$ & $83(26)$ & $80(25.8)$ & $163(26.3)$ & \\
\hline & $901-1700$ & $65(21)$ & $87(28)$ & $152(24.5)$ & \\
\hline & $\geq 1701$ & $63(20)$ & $73(23.6)$ & $136(22)$ & \\
\hline \multirow[t]{3}{*}{ Age at time first sex } & $\leq 14$ & $63(20)$ & $20(6.5)$ & $83(13.4)$ & 0.00 \\
\hline & $15-17$ & $87(28)$ & $85(27.4)$ & $172(28)$ & \\
\hline & $\geq 18$ & $160(21.6)$ & $205(66)$ & $365(58.9)$ & \\
\hline \multirow[t]{2}{*}{ Previous history of marriage } & No & $10(3.2)$ & $16(5.2)$ & $26(4.2)$ & 0.229 \\
\hline & Yes & $300(96.8)$ & $294(95)$ & $594(95.8)$ & \\
\hline \multirow[t]{4}{*}{ Duration of live in marriage } & $\leq 5$ & $100(32.3)$ & $149(48)$ & $249(40.2)$ & 0.00 \\
\hline & $6-10$ & $72(23)$ & $75(24.2)$ & $147(23.7)$ & \\
\hline & $11-15$ & $46(14.8)$ & $36(11.2)$ & $82(13)$ & \\
\hline & $\geq 16$ & $92(30)$ & $50(16)$ & $142(23)$ & \\
\hline \multirow{3}{*}{$\begin{array}{l}\text { Age difference between the } \\
\text { partner at first intercourse }\end{array}$} & Equal & $40(13)$ & $69(22.3)$ & 109 (17.6) & 0.00 \\
\hline & $<5$ years & $56(18)$ & $90(29)$ & $146(23.6)$ & \\
\hline & $\geq 5$ years & $214(69)$ & $151(48.7)$ & $365(59)$ & \\
\hline \multirow[t]{2}{*}{ Type of marriage } & Monogamous & $239(77)$ & $242(78)$ & 481 (77.6) & 0.773 \\
\hline & Polygamous & $71(23)$ & $68(22)$ & $139(22.4)$ & \\
\hline
\end{tabular}

$P$ value of pearson's chi square test to compare cases and controls

Maternal age, residence of the respondent, marital status, educational status, family income, age at first sex, age difference with partner at first sexual intercourse and duration of relationship found to have a significant association on the bivariate analysis; these variables further fitted into a multivariate logistic regression model.

Advanced maternal age was found to be significantly associated with higher odds of adverse pregnancy outcome. Mothers in the age group 35-44 years of age were 2.5 times more likely to counter an adverse pregnancy outcome AOR 2.54 (95\% CI 1.27, 5.06) similarly mothers in the age $45-54$ years were significantly associated with adverse pregnancy outcome AOR 2.79 (95\% CI 1.27, 6.16).

Educational status also showed a significant association with adverse pregnancy outcome. Those mothers with no formal education were 2 times more likely to develop an adverse pregnancy outcome AOR 2.15 (95\% CI 1.41, 2.81) and mothers with primary education were 1.6 times more 
Table 2 The univariate and multivariate analysis of the determinants of adverse pregnancy outcome for different explanatory variables categories, Debre Tabor town, Northwest Ethiopia

\begin{tabular}{|c|c|c|c|c|c|}
\hline Variables & Category & Cases, $\mathrm{n}=\mathbf{3 1 0}(\%)$ & Control, $n=310(\%)$ & COR $(95 \% \mathrm{Cl})$ & AOR $(95 \% \mathrm{Cl})$ \\
\hline \multirow[t]{5}{*}{ Maternal age } & $\leq 24$ & $22(7.1)$ & $52(16.8)$ & 1 & 1 \\
\hline & $25-34$ & $79(25.5)$ & $139(44.8)$ & $1.34(0.76,2.37)$ & $1.15(0.63,2.1)$ \\
\hline & $35-44$ & $80(25.8)$ & $60(19.35)$ & $3.15(1.73,5.74)^{*}$ & $2.54(1.27,5.06)^{*}$ \\
\hline & $45-54$ & $68(22)$ & $38(12.3)$ & $4.23(2.24,7.99)^{*}$ & $2.79(1.27,6.16)^{*}$ \\
\hline & $\geq 55$ & $61(21.9)$ & $21(6.8)$ & $6.86(3.39,13.87)^{*}$ & $4.18(1.73,9.13)^{*}$ \\
\hline \multirow[t]{2}{*}{ Residence } & Rural & $112(36.1)$ & $83(26.8)$ & $1.55(1.09,2.18)^{*}$ & $1.51(1.03,2.21)^{*}$ \\
\hline & Urban & $198(63.9)$ & $227(73.2)$ & 1 & 1 \\
\hline \multirow[t]{4}{*}{ Marital status } & Married & $199(64.2)$ & $235(75.8)$ & 1 & 1 \\
\hline & Divorced & $54(17.4)$ & $37(12)$ & $1.72(1.08,2.73)^{*}$ & $1.08(0.64,1.83)$ \\
\hline & Widowed & $40(13)$ & $17(5.5)$ & $2.78(1.53,5.05)^{*}$ & $1.02(0.5,2.07)$ \\
\hline & Separated & $17(5.5)$ & $21(6.8)$ & $0.96(0.49,1.86)$ & $0.95(0.46,1.93)$ \\
\hline \multirow[t]{4}{*}{ Educational status } & No formal education & $174(56)$ & $171(55.2)$ & $2.37(0.89,6.32)$ & $2.15(1.41,2.81)^{*}$ \\
\hline & Primary education & $94(30.3)$ & $79(25.5)$ & $2.77(1.01,7.56)^{*}$ & $1.6(1.06,4.6)^{*}$ \\
\hline & Secondary education & $36(12)$ & $46(14.8)$ & $1.83(0.64,5.22)$ & $1.45(0.48,1.93)$ \\
\hline & Higher education & $6(2)$ & $14(4.5)$ & 1 & 1 \\
\hline \multirow[t]{2}{*}{ Job status } & Unemployed & $218(70.3)$ & $202(65.2)$ & $1.23(0.9,1.77)$ & \\
\hline & Employed & $92(30)$ & $108(34.8)$ & 1 & \\
\hline \multirow[t]{4}{*}{ Family income categorized } & $\leq 560$ & $99(32)$ & $70(22.6)$ & $1.6(1.03,2.58)^{*}$ & $1.23(0.72,2.11)$ \\
\hline & $561-900$ & $83(26)$ & $80(25.8)$ & $1.2(0.76,1.89)$ & $1.14(0.68,1.94)$ \\
\hline & $901-1700$ & $65(21)$ & $87(28)$ & $0.86(0.54,1.38)$ & $0.93(0.56,1.57)$ \\
\hline & $\geq 1701$ & $63(20)$ & $73(23.6)$ & 1 & 1 \\
\hline \multirow[t]{3}{*}{ Age at time first sex } & $\leq 14$ & $63(20)$ & $20(6.5)$ & $4.03(2.34,6.95)^{*}$ & $2.29(1.25,4.23)^{*}$ \\
\hline & $15-17$ & $87(28)$ & $85(27.4)$ & $1.31(0.911,1.88)$ & $1.32(0.89,2.19)$ \\
\hline & $\geq 18$ & $160(21.6)$ & $205(66)$ & 1 & 1 \\
\hline \multirow[t]{4}{*}{ Duration of relationship } & $\leq 5$ & $100(32.3)$ & $149(48)$ & 1 & 1 \\
\hline & $6-10$ & $72(23)$ & $75(24.2)$ & $1.43(0.95,2.16)$ & $1.3(0.86,2.19)$ \\
\hline & $11-15$ & $46(14.8)$ & $36(11.2)$ & $1.90(1.14,3.15)^{*}$ & $1.04(0.57,1.92)$ \\
\hline & $\geq 16$ & $92(30)$ & $50(16)$ & $2.74(1.79,4.2)^{*}$ & $1.24(0.68,2.28)$ \\
\hline \multirow[t]{2}{*}{ Previous history of marriage } & Yes & $300(96.8)$ & $294(95)$ & $1.63(0.73,3.65)$ & \\
\hline & No & $10(3.2)$ & $16(5.2)$ & 1 & \\
\hline \multirow{3}{*}{$\begin{array}{l}\text { Age difference between the } \\
\text { partner at first intercourse }\end{array}$} & No difference & $40(13)$ & $69(22.3)$ & 1 & 1 \\
\hline & $<5$ years & $56(18)$ & $90(29)$ & $1.07(0.64,1.79)$ & $1.07(0.6,1.89)$ \\
\hline & $\geq 5$ years & $214(69)$ & $151(48.7)$ & $2.44(1.57,3.80)^{*}$ & $1.74(1.07,2.83)^{*}$ \\
\hline \multirow[t]{2}{*}{ Type of marriage } & Monogamous & $239(77)$ & $242(78)$ & Ref & \\
\hline & Polygamous & $71(23)$ & $68(22)$ & $1.05(0.72,1.54)$ & \\
\hline
\end{tabular}

$1=$ Reference

${ }^{*} P<0.05$

${ }^{* *} P<0.01$

likely to have an adverse pregnancy outcome compared to those in higher education AOR 1.6 (95\% CI 1.06, 4.6).

Women living in rural area were twice as likely to be at risk of adverse pregnancy outcome compared to women living in urban AOR 1.51 (95\% CI 1.03, 2.21). The odds of adverse pregnancy outcome were higher among women with $\geq 5$ years age difference with their partner at first sex compared to those with zero age difference AOR 1.74 $(95 \%$ CI 1.07, 2.83). Early debut for sex was also associated with adverse pregnancy outcome among mothers. Odds of adverse pregnancy outcome were two times higher among women who started sex less than 14 years age compared to those who started sex $\geq 18$ years of age AOR 2.29 (95\% CI 1.25, 4.23) (Table 2). 


\section{Discussion}

This study was conducted to identify socioeconomic and demographic factors associated with adverse pregnancy outcome in Debre Tabor town, Northwest Ethiopia.

In our study, advanced maternal age has showed a strong association with adverse pregnancy outcome. In line with this finding several studies done in different areas have revealed similar findings that older age was associated with higher odds of stillbirth [13, 22, 23]. Study done in Denmark on a nationally representative survey, which have showed advanced maternal age is the risk of adverse pregnancy outcome [20]. This might be due to the aging process in the ovaries [24].

The finding also revealed that as the age of the mother increases the association with an adverse pregnancy outcome becomes stronger. While a multicounty analysis of the effect of maternal age on adverse pregnancy outcome showed a higher risk among adolescent mothers [25]. This difference might be attributed to the difference in measurement as the study was comparing risk of adverse outcome among early and late adolescent mothers. This can be explained because early pregnancy is highly associated with immature physiologic maternal change which can lead to a higher risk [26, 27].

Mothers with low educational status were also at risk of developing an adverse pregnancy outcome compared to the mother with a higher education. This was in line with the study done in the Amhara region of Ethiopia, which found low education was associated with higher odds of adverse pregnancy outcome [13]. As having lower educational status was accompanied by low maternal and neonatal service utilization. A study has also shown a high tendency of using maternity waiting home among educated women [22]. This finding was opposed by the studies which indicated high rates of abortions among those with higher education $[9$, $11]$.

On the other side early sexual debut was significantly associated with adverse pregnancy outcome AOR 2.29 (95\% CI 1.25, 4.23). This finding was similar with a study done in Australia, which revealed early sexual initiation associated with adverse pregnancy outcome [28].

\section{Conclusions}

Advanced maternal age, low educational status, early sexual debut and age difference with a partner of 5 years and above during the first sexual intercourse, have showed increased the odds of adverse pregnancy outcome.

\section{Limitation of the study}

- Determination of the outcome variable totally depended on the study participant memory and awareness on the issue.

- This study is limited to socioeconomic and demographic factors.

\section{Abbreviations}

AOR: adjusted odds ratio; Cl: confidence interval; MDGs: Millennium Developmental Goals; MMR: maternal mortality ratio; LMIC: lower and middle income countries; EDHS: Ethiopian Demographic and Health Survey; WHO: World Health Organizations.

\section{Authors' contributions}

All the authors (ASK, AAM, AGA) conceptualized research problem, designed the methods and analyzed the data. All authors read and approved the final manuscript.

\section{Author details}

${ }_{1}^{1}$ Pan Africa University Life and Earth Sciences Institute (PAULESI), University of Ibadan, Ibadan, Nigeria. ${ }^{2} 1000$ Days Plus Project, Department of Reproductive and Health Service Management, Addis Ababa University, Addis Ababa, Ethiopia. ${ }^{3}$ Department of Epidemiology and Biostatistics, Institute of Public Health, University of Gondar, Gondar, Ethiopia. ${ }^{4}$ Amhara Public Health Institute, Public Health Emergency Management Directorate, Bahirdar, Ethiopia.

\section{Acknowledgements}

The authors are grateful to the data collectors and study participants.

\section{Competing of interests}

The authors declare that they have no competing interests.

\section{Availability of data and materials}

All data pertaining to this study are available from the corresponding authors.

\section{Consent for publication \\ Not applicable.}

\section{Ethics approval and consent to participate}

Letter of support and ethical clearance was obtained from the Department of Obstetrics and Gynecology, University of Ibadan and Pan African University Institute of Life and Earth Sciences (PAULESI). Letter of permission to conduct the study was collected from the South Gonder zone health department and permission from pertinent bodies were secured. Written informed consent was obtained from all the study participants. All the important ethical procedures were followed to keep the confidential the information of the study participants.

\section{Funding}

There is no funding received for this study.

\section{Publisher's Note}

Springer Nature remains neutral with regard to jurisdictional claims in published maps and institutional affiliations.

Received: 16 October 2018 Accepted: 14 November 2018 Published online: 19 November 2018 


\section{References}

1. Alkema $L$, et al. Global, regional, and national levels and trends in maternal mortality between 1990 and 2015, with scenario-based projections to 2030: a systematic analysis by the UN Maternal Mortality Estimation Inter-Agency Group. Lancet. 2016;387(10017):462-74.

2. World Health Organization. Trends in maternal mortality: 1990 to 2015 : estimates by WHO, UNICEF, UNFPA, World Bank Group and the United Nations Population Division. Geneva: World Health Organization; 2015.

3. Say L, et al. Global causes of maternal death: a WHO systematic analysis. Lancet Glob Health. 2014;2(6):e323-33.

4. Bhutta ZA, Reddy KS. Achieving equity in global health: so near and yet so far. JAMA. 2012;307:19.

5. Awiti JO. Preceding birth interval length and maternal health in Kenya. Kenya: University of Nairobi; 2013.

6. Lee $A C$, et al. National and regional estimates of term and preterm babies born small for gestational age in 138 low-income and middle-income countries in 2010. Lancet Glob Health. 2013;1(1):e26-36.

7. Grimes DA, et al. Unsafe abortion: the preventable pandemic. Lancet. 2006;368(9550):1908-19.

8. United Nations Department of Economic and Social Affairs. World Population Prospects: the revision, highlights, working paper. New York: United Nations Department of Economic and Social Affairs; 2009.

9. Asiki G, et al. Adverse pregnancy outcomes in rural Uganda (1996-2013): trends and associated factors from serial cross sectional surveys. BMC Pregnancy Childbirth. 2015;15:279.

10. Padhi BK, et al. Risk of adverse pregnancy outcomes among women practicing poor sanitation in rural india: a population-based prospective cohort study. PLoS Med. 2015;12(7):e1001851.

11. Sadiq AA, et al. Factors associated with adverse pregnancy outcomes and perceptions of risk factors among reproductive age women in Soba LGA, Kaduna State 2013. Pan Afr Med J. 2016:25:111.

12. Adane AA, et al. Adverse birth outcomes among deliveries at Gondar University Hospital, Northwest Ethiopia. BMC Pregnancy Childbirth. 2014; 14:90.

13. Lakew D, Tesfaye D, Mekonnen H. Determinants of stillbirth among women deliveries at Amhara region, Ethiopia. BMC Pregnancy Childbirth. 2017;17(1):375

14. Lynch J, et al. Income inequality, the psychosocial environment, and health: comparisons of wealthy nations. Lancet. 2001;358(9277):194-200.

15. Herny Erdawati Mohd Rashed SMA, Noor Ani Ahmad NH, Zubidah Md FA, Kamarul Ariffin S, Rafedah M, Nur Intan Mohdlthnin ZOTA. Advanced maternal age and adverse pregnancy outcomes in Muar, Johor, Malaysia. Sains Malaysiana. 2016;45(10):5.

16. Yeshialem Eyosiyas, et al. Determinants of adverse pregnancy outcomes among mothers who gave birth from Jan 1-Dec 312015 in Jimma University Specialized Hospital, Case control study, 2016. Med Clin Rev. 2016;3:22.

17. Authority CS. Population and housing census of Ethiopia. Addis Ababa: Authority CS; 2012.

18. Tesfaye G, Hambisa MT, Semahegn A. Induced abortion and associated factors in health facilities of Guraghe zone, southern Ethiopia. J Pregnancy. 2014;2014:295732.

19. Dbstet A. WHO: recommended definitions, terminology and format for statistical tables related to the perinatal period and use of a new certificate for cause of perinatal deaths. Acta Obstet Gynecol Scand. 1977;56(3):247-53.

20. Frederiksen LE, et al. Risk of adverse pregnancy outcomes at advanced maternal age. Obstet Gynecol. 2018;131(3):457-63.

21. Joseph KS, et al. Rationale and recommendations for improving definitions, registration requirements and procedures related to fetal death and stillbirth. BJOG. 2017;124(8):1153-7.

22. Braat $F$, et al. Comparison of pregnancy outcomes between maternity waiting home users and non-users at hospitals with and without a maternity waiting home: retrospective cohort study. Int Health. 2018;10(1):47-53.

23. Ediris Mekiya, et al. Disparities in adverse pregnancy outcomes between advanced maternal age and younger age in Ethiopia: institution based comparative cross-sectional study. Int J Nurs Midwifery. 2018;10(6):54-61.

24. Waldenstrom $U$, et al. Adverse pregnancy outcomes related to advanced maternal age compared with smoking and being overweight. Obstet Gynecol. 2014;123(1):104-12.

25. Laopaiboon $M$, et al. Advanced maternal age and pregnancy outcomes: a multicountry assessment. BJOG. 2014;121(Suppl 1):49-56.

26. Ganchimeg T, et al. Pregnancy and childbirth outcomes among adolescent mothers: a World Health Organization multicountry study. BJOG. 2014;121(Suppl 1):40-8

27. Kirchengast S. Maternal age and pregnancy outcome-an anthropological approach. Anthropol Anz. 2007;65(2):181-91.

28. Kirchengast S, Mayer M, Voigt M. Pregnancy outcome is associated with maternal marital status in Austria-even at the beginning of the 21st century. Anthropol Anz. 2007;65(4):415-26.
Ready to submit your research? Choose BMC and benefit from:

- fast, convenient online submission

- thorough peer review by experienced researchers in your field

- rapid publication on acceptance

- support for research data, including large and complex data types

- gold Open Access which fosters wider collaboration and increased citations

- maximum visibility for your research: over $100 \mathrm{M}$ website views per year

At BMC, research is always in progress.

Learn more biomedcentral.com/submissions 